\title{
Temas para um Programa de Tutoria em Medicina: uma Investigação das Necessidades dos Alunos da FMUSP
}

\author{
Topics for a Mentoring Program in \\ Medicine: a survey of student needs at the \\ University os São Paulo School of Medicine
}

Patrícia Lacerda Bellodi ${ }^{1}$

Tânia Martinho²

Bianca Massaroppe

Milton de Arruda Martins ${ }^{4}$

Marco Antônio Silva dos Santos

PAL.AVRAS-CHAVE:

- Estudantes de Medicina;

Fducação Médica;

- Turotia

KEY-WORDS:
-Estudents, Medical
- Education, Medical
-Mentorship

Recebido em: 02/09/2003

Reencaminhado em:06/04/2004

Recncaminhadoem:07/06/2004

Recncuminhadoem:22/06/2004

Aprovado em: 30/06/2004

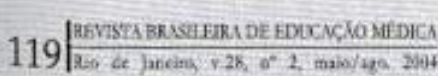

\begin{abstract}
RESUMO
É fundamental a imvestigação das necessidades do aluno para subsidiar as intervençoes a ele destinadas. Na implementaçå do Programa Tutores na Faculdade de Medicina da Universidade de São Paulo, os temas indicados pelos alunos para o programa mostraram que, em todos os anos e desde o infcio do curso, estes buscam especialmente orientaçao relacionada ao futuro profissional. As questżes de ensino-aprendizagem săo muito importantes para os alunos do ciclo básico e clínico, enquanto para os alunos do internato o tema 'relaça médico-paciente' é prioritário. O grupo de respostas relativas a "ser aluno de medicina" aparece depois, seguido por "ética médica". Aparecem na seqüência outros temas, como 'ser médico', 'temas médicos diversos', 'faculdade e universidade' e 'medicina e sociedade: Os temas menos citados pelos alunos em geral săo aqueles relacionados à vida pessoal e temas fora da área médica. O temário elaborado teve um importante papel para os futuros tutores durante seu treinamento: evidenciou as principais áreas de interesse dos alunos, imostrou as diferenças ao longo dos vários anos e permitiu vislumbrar as possiveis utilizaçøes do espaço da tutoria.
\end{abstract}

\begin{abstract}
Investigation of students' needs is crucial for backing measures that target their experience. In the implementation of the Mentoring Program at the University of Sao Paulo Medical School, the themes recommended by students for the program showed that in every year of their medical schooling, what is most important is counseling in relation to their future career practice. Teaching-learning issues are highly important for students in both their basic and initial clinical training, while for interns the "physician-patient" relationship is the priority. The set of answers related to "being a medical student" appears later, followed by "medical ethics". Next come other themes such as "being a doctor", "various medical topics", "medical school and university", and "medicine and society". The themes less frequently mentioned by students in general are those related to personal life and issues outside of the medical field. The set of themes had an important role for future mentors during their training, highlighting the principal areas of interest for students, demonstrating differences over the course of their years of training, and allowing one to glimpse the potential uses of mentorship.
\end{abstract}

\footnotetext{
'Doutona em Psicologia,Coordenação Técnica do Programa Tutores FMUSP, Centro de Desentolvimento em Educaçâo Médica - Cendem, Faculdade de Medicina da Universidade de Silo Paulo - FMUSP, Sïo Paulo, Brasil.

${ }^{2}$ Represenfante Discente na Coondenação Genal do Programa Tutores (2001) Faculdade de Medicina da Universidade de São Paulo - FMUSP, Säo Paulo, Brasil.

${ }^{3}$ Representante Discente na Coondenação Geral do Programa Tutones (2001) Faculdade de Medicina da Unioersidade de Sīo Paulo - FMUSP, Salo Paulo, Brasill.

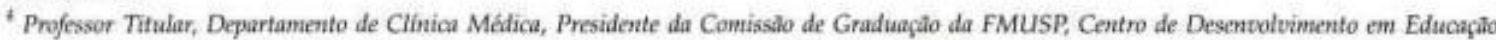
Medica - Cedem, Faculdade de Medicina da Unioersidade de Såo Paulo - FMUSP, São Paulo, Brasil.

${ }^{5}$ Representante Discente na Coondeną̧ăo Geral do Programa Tutores (2001) Faculdade de Medicina da Universidade de Săo Paulo - FMUSP, São Paulo, Brasil.
} 


\section{INTRODUÇão}

O caminho de formação do futuro médico é extenso e intenso. São seis anos de conhecimentos, habilidades e atitudes a serem desenvolvidos, numa convivência quase integral com colegas e professores, em novos e diferentes ambientes de aprendizagem.

Independentemente das estruturas das diferentes escolas médicas, há no processo de formação momentos críticos, geradores de estresse e de caráter até mesmo previsível ${ }^{1,2,3}$. Destacam-se entre eles a entrada na faculdade, os anos básicos distanciados da aplicação clínica, o contato com o cadáver e a morte, a entrada no hospital, o primeiro paciente, o contato com as diferentes áreas durante o internato. Ao final do curso, mais um importante momento de decisão: a escolha da especialidade e o desafio da entrada na residência desejada. Essa escolha exige do aluno, entre outros fatores, que ele considere quem é, o que quer fazer, como e à maneira de quem, especialmente fazendo-o lembrar dos profissionais com quem se relacionou durante a faculdade ${ }^{4}$.

Além disso, a estrutura curricular de várias escolas tem permitido, atualmente, a composição de um currículo personalizado, em que, além das disciplinas obrigatórias, matérias optativas podem ser selecionadas pelo aluno a partir de suas necessidades e interesses.

O desenrolar de todo o processo de formação, especialmente em relação às escolhas a realizar, pode ser muito facilitado se for oferecido ao aluno contato com modelos identificatórios adequados e estimulantes para suas diferentes necessidades.

Entretanto, o cotidiano observado informalmente e em muitos estudos em educação médica é caracterizado pelo anonimato, pelo distanciamento entre professores e colegas, e pela solidão no enfrentamento dos problemas - sejam eles acadêmico-profissionais ou de ordem pessoal ${ }^{5,6}$.

Considerando este contexto, a presença de uma figura de suporte para o caminhar profissional do aluno - um tutor ou mentor - aparece no cenário da educação médica por meio de uma série de propostas, denominadas Faculty Mentoring Programmes, Tutoring Systems, Personal Tutoring Systems e Student Counseling Systems ${ }^{6}$.

Em 2001, atenta e preocupada com esse panorama da formação médica, a Faculdade de Medicina da Universidade de São Paulo (FMUSP) implanta um sistema de Tutoria (Mentoring) - o Programa Tutores FMUSP.

\section{O Programa Tutores FMUSP: Objetivos, Estrutura e Funcionamento}

O Programa Tutores FMUSP tem como objetivo principal oferecer a todos os alunos da faculdade uma figura de supor- te e referência durante sua formação, que promova e facilite a troca de experiências entre os diferentes anos e contribua para a integração do conhecimento e do curso como um todo ${ }^{7}$.

O programa é estruturado em cinco núcleos fundamentais: o grupo de tutores (um tutor para cada 10 a 12 alunos); os alunos (de todos os anos, divididos aleatoriamente pelos grupos, com pelo menos um de cada período acadêmico); o grupo de supervisores (um supervisor - profissional com experiência em processos grupais - que orienta um grupo de dez tutores em média); a equipe técnica (composta por uma psicóloga e uma pessoa responsável pela administração cotidiana das informaç̃es); e a coordenação geral (composta por representantes de tutores, supervisores, alunos e a própria equipe técnica).

O Tutor FMUSP é um médico experiente, com conhecimento da graduaçăo e bom contato com os alunos. Foi selecionado a partir desse perfil, participou de treinamento inicial e é supervisionado mensalmente em sua atividade. Está disponível para encontros com seus alunos, seja em grupo, seja individualmente, sempre que necessário. Promove, no mínimo, um encontro mensal com um grupo de 10 a 12 alunos de diferentes anos (pelo menos um de cada período acadêmico) para discussão e orientação de questões diversas (acadêmicas, profissionais, pessoais e sociais). Nesses momentos grupais, facilita especialmente a troca de experiência entre os alunos e, com isso, acaba por integrar não apenas os alunos entre si, mas o próprio curso e seus diferentes conteúdos ao longo do tempo.

Para atuar nesse papel, é assessorado de perto por um supervisor - profissional da área de psicologia, psiquiatria ou psicanálise - , que, com seus conhecimentos em fenômenos grupais, o capacita a compreender, a refletir e a lidar com seu grupo de alunos. Periodicamente, cada dez tutores se reúnem com seu supervisor nessa atividade de capacitação continuada para o seu desenvolvimento como tutor.

Quando surgem problemas específicos, de ordem psicológica ou pedagógica, o tutor, com o auxílio de seu supervisor, é orientado quanto à melhor forma de encaminhar a questão. A FMUSP conta com duas instâncias de suporte aos alunos: o Grapal (Grupo de Apoio Psicológico ao Aluno de Medicina) e o Cedem (Centro de Desenvolvimento de Educação Médica), que, respectivamente, focalizam em especial questões emocionais e pedagógicas.

Outros temas surgidos nos encontros entre tutor e tutorandos podem ser encaminhados também à Comissão de Graduação da Faculdade. Há, inclusive, tutores representantes da Comissão de Graduação na Coordenação Geral do programa, o que viabiliza ainda mais esse canal. 


\section{Os Alunos da FMUSP e o Programa Tutores}

Sendo o Programa Tutores uma iniciativa para o aluno e com o aluno, conhecer suas necessidades e tê-lo como parceiro em sua realização têm sido uma preocupaçăo constante da coordenação.

Os alunos da FMUSP estiveram presentes em vários momentos do projeto. Foram convidados a tomar parte das discussōes iniciais para apresentação da proposta e participaram depois de grupos de opinião a respeito de aspectos específicos do projeto.

Antes do início do programa, elaboraram um questionário para investigação de temas a serem discutidos nos encontros de tutoria que pudessem refletir e indicar ao tutor as necessidades, problemas e desafios que encontraram durante $o$ curso. Também fizeram consultas entre si para indicaçăo de professores da escola para o papel de tutor, dando subsídios importantes ao processo seletivo.

Colaboraram ainda na discussão sobre as mais adequadas possibilidades de inserção da tutoria na grade horária do curso. Finalmente, participaram das reuniōes da Coordenação Geral do programa como representantes discentes.

\section{Temário do Programa Tutores}

O temário do Programa Tutores constitui-se, então, no elenco de temas surgidos a partir da consulta feita pelos próprios alunos a seus colegas dos diferentes anos.

Ele não tem o caráter de "programa de disciplina", nem deve ser obrigatoriamente seguido pelos diferentes grupos. $\mathrm{O}$ tutor pode recorrer a ele nos momentos em que questões não mobilizem o grupo para a discussão, assim como pode apresentá-lo aos alunos como um "banco" de assuntos a serem escolhidos, numa determinada ondem, se eles assim o quiserem. Em resumo, apresenta-se como um instrumento "de bolso", de suporte para o tutor e o grupo, sendo as questōes emergentes nos encontros aquelas consideradas prioritárias na atividade.

O temário teve grande importância durante o treinamento dos tutores antes do início das atividades. Ele mostrou a diversidade de temas que poderiam ser discutidos nos encontros, as necessidades e expectativas dos alunos e especialmente a diferença de interesses entre os diferentes anos e ciclos do curso. Sendo os grupos de tutoria heterogêneos, isto é, compostos por pelo menos um aluno de cada ano do curso, conhecer tais diferenças foi particularmente importante.

\section{Objetivos}

Este trabalho tem como objetivo descrever o processo de construção do temário no momento de implantação do Programa Tutores na FMUSP e:
- Apresentar os principais temas surgidos;

- Comparar a distribuição dos temas entre os ciclos básico, clínico e internato;

- Discutir os resultados obtidos, no contexto da formação médica durante a graduação.

\section{Metodologia}

Todos os alunos da FMUSP, do $1^{9}$ ao $6^{9}$ ano, foram convidados a responder o questionário elaborado pelos representantes discentes no Programa Tutores. $O$ instrumento utilizado continha apenas três questōes abertas:

- Que tema você gostaria de discutir com seu tutor?

- Que professor da faculdade você gostaria de ter como tutor?

- Que professor da faculdade você não gostaria de ter como tutor?

Os questionários - cujo preenchimento era voluntário - foram entregues em visitas a salas de aula ou ambulatórios/enfermarias em que os alunos estivessem cursando suas disciplinas ou estágios do internato.

As respostas obtidas foram analisadas e classificadas segundo princípios de análise de conteúdo, isto é, após a leitura de todo o material obtido, foram estabelecidos núcleos temáticos e respectivas categorias e freqüências.

Para a comparação entre os grupos (ciclo básico, clínico e internato), utilizou-se estatística descritiva e o teste do quiquadrado, com o nível de significância $\mathrm{p}<0,05$.

\section{RESULTADOS}

\section{Retorno dos Respondentes}

A taxa de resposta dos alunos da FMUSP foi de $19 \%$, isto é, 201 alunos do total de alunos da faculdade $(n=1.080)$ retornaram aos pesquisadores o questionário preenchido: 76 (21\%) do ciclo básico, $42(12 \%)$ do ciclo clínico e $63(23 \%)$ do internato.

\section{Grupos Temáticos: Categorias e Subcategorias}

As respostas obtidas foram categorizadas nos seguintes 12 grupos temáticos, com categorias e subcategorias:

VIDA PESSOAL: Lazer (lazer do aluno; lazer do médico); Família (conciliar família e faculdade; relações familiares do médico).

ENSINO-APRENDIZAGEM: Administração do tempo (tempo para estudar; tempo livre; janelas/horários/carga horária); Métodos de estudo (rotina de estudos; organização do estudo; o quê e como aprender; seleção do conteúdo realmente importante; estudo em casa); Professores (avaliação e 
relacionamento; avaliação de professores; falta de didática; problemas com professores; hierarquia; relacionamento com assistente/preceptor; relacionamento professor-aluno); Currículo (avaliação do currículo nuclear, disciplinas optativas, como escolher, grau de importância, discussão do que deve ser mantido, melhorado ou tirado, defeitos e qualidades); Internato (panelas, rodízios); Graduação em geral (avaliação da qualidade do curso; nível das disciplinas; conteúdo e utilidade disciplinas; deficiências na formação/lacunas; reformulação); Ensino médico (discussões a respeito do ensino médico; educação médica no Brasil; formação humanística do médico; formação profissional em geral).

ÉTICA MÉDICA: Bioética (aborto, eutanásia, clonagem, dignidade humana, questões dilemáticas de decisão, temas polêmicos); Erro médico (responsabilidade, processos, leis).

RELAÇÃO MÉDICO-PACIENTE: Morte (pacientes terminais; como enfrentar dor/morte; cuidados paliativos); Sexualidade (sexo; sexualidade relação médico-paciente; assédio sexual relação médico-paciente); Dificuldades na relação (agressividade; paciência; amor ao paciente; envolvimento emocional; comunicaçăo com paciente e família; como lidar com o sofrimento; situações embaraçosas; conflitos; respeito; aspectos psicológicos).

DESENVOLVIMENTO PROFISSIONAL E DE CARREIRA: Atividades extracurriculares (importância e relevância, possibilidades de pesquisa, orientaçăo trabalhos científicos, fazer ou não?); Escolha da especialidade (orientação sobre as atividades de cada uma, quais são as especializaçōes, temas ligados às especialidades médicas, perspectivas de cada uma, campo profissional, carreira); Residência (prova, cotidiano, carga horária, funcionamento; orientação, acesso, graduando FMUSP x residência FMUSP); Mercado de trabalho (tendências, emprego, dificuldades na profissão, remuneraçāo, salário, concorrência); Futuro da medicina (perspectivas, novas fronteiras, tendências); Atualização conhecimento médico (novos, renovação, inovações, como acompanhar, aplicação na prática).

FACULDADE E UNIVERSIDADE: FMUSP (melhoria do ambiente/condiçōes da FMUSP; problemas internos da FMUSP; problemas com a FMUSP; decadência da FMUSP; futuro da FMUSP; graduação FMUSP x graduação ideal); Universidade em geral (pesquisa, extensão; contexto brasileiro, latino-americano e mundial; carreira acadêmica).

SER ALUNO DE MEDICINA: Vocação médica (escolha da medicina; crises de desistência; motivação); Curso médico ao longo do tempo (choque ao entrar na faculdade/desencanto; os primeiros anos; dificuldades de cada ano; frustraçōes; traumas e transições psicológicas no curso médico; apoio durante o curso); Qualidade de vida do aluno (vida do aluno na FMUSP; aproveitamento época de estudante; contato com o mundo); Problemas acadêmicos (diversos); Problemas emocionais (pressão psicológica; cansaço; drogas; estresse; depressão; ansiedade; avaliação psiquiátrica); Relacionamento com colegas (competição; relações interpessoais); Direitos e deveres (direitos do aluno na FMUSP; conduta do aluno; responsabilidade).

SER MÉDICO: Qualidade de vida do médico (saúde mental; cuidar de si mesmo; estresse); Cotidiano profissional (dia-a-dia; conciliação vida pessoal e profissional; conduta primeiros anos de formado; dificuldades profissão; aspectos financeiros).

MEDICINA E SOCIEDADE: Trabalho social (trabalhos sociais junto à comunidade; trabalho voluntário); Política e Sistema de Saúde no Brasil (realidade situação hospitais fora do HC; burocracia hospitalar; SUS, PAS, convênios; estrutura Sistema Saúde).

TEMAS MÉDICOS: Disciplinas específicas (anatomia, fisiologia, bioquímica, biologia molecular, anatomia do aparelho locomotor, neuroanatomia, propedêutica, psicologia médica, pronto socorro); Casos clínicos (temas da prática médica; desafios no diagnóstico; terapêutica; abordagem clinica); Temas médicos diversos (medicina baseada em evidências; medicina alternativa; história da medicina; medicina e economia).

TEMAS NÃO MÉDICOS: Temas não médicos diversos (astronomia; física quântica; assuntos fora da medicina; cultura em geral; filmes / cinema / arte / TV / revistas).

NÃO INDICAÇÃO DE TEMAS: Sem opinião ("Sei lá", "Não sei", "Não tenho uma idéia sobre os temas", "Se os caras forem bons eles saberão...").

A Tabela 1 mostra a distribuição dos diferentes grupos temáticos entre os três ciclos, assim como os resultados da análise estatística para comparação entre eles.

Observa-se que, em todos os anos e desde o início do curso, os alunos (média de $48 \%$ entre os anos) mostram buscar orientação relacionada ao futuro profissional (mercado de trabalho e escolha da especialidade, especialmente).

As questōes de ensino-aprendizagem (métodos de estudo, administração do tempo, escolha de disciplinas optativas, por exemplo) são significativamente $(\mathrm{p}<0,001)$ importantes para os alunos do ciclo básico (37\%) e clínico (43\%), ao passo que para os alunos do internato $(43 \%)$ o tema "relação médico-paciente" é prioritário $(\mathrm{p}=0,012)$.

Em seguida, pode-se observar que $25 \%$ de todos os respondentes não indicaram temas em suas respostas, não havendo diferença șignificativa entre os ciclos. 
Tabela A.1

Distribuição dos temas entre os ciclos básico, clínico e internato

\begin{tabular}{|c|c|c|c|c|c|c|}
\hline Temas & $\begin{array}{c}\text { Ciclo básico } \\
n=76\end{array}$ & $\begin{array}{l}\text { Ciclo clinico } \\
\quad n=42\end{array}$ & $\begin{array}{c}\text { Internato } \\
n=83\end{array}$ & $\begin{array}{c}\text { Respondentes } \\
n=201\end{array}$ & $\begin{array}{c}\text { chi- } \\
\text { quadrado }\end{array}$ & $p$ \\
\hline \multirow{2}{*}{$\begin{array}{c}\text { Desenvolvimento } \\
\text { profissional/carreira* }\end{array}$} & 36 & 28 & 32 & 96 & \multirow{2}{*}{8,84} & \multirow{2}{*}{0,012} \\
\hline & $47 \%$ & $67 \%$ & $39 \%$ & $48 \%$ & & \\
\hline \multirow{2}{*}{ Ensino-Aprendizagem ${ }^{*}$} & 28 & 18 & 10 & 56 & \multirow{2}{*}{18,08} & \multirow{2}{*}{$<0,001$} \\
\hline & $37 \%$ & $43 \%$ & $12 \%$ & $28 \%$ & & \\
\hline \multirow{2}{*}{ Relação Médico-Paciente* } & 14 & 5 & 36 & 55 & \multirow{2}{*}{18,81} & \multirow{2}{*}{$<0,001$} \\
\hline & $18 \%$ & $12 \%$ & $43 \%$ & $27 \%$ & & \\
\hline \multirow{2}{*}{ Não indicação de temas } & 21 & 8 & 22 & 51 & \multirow{2}{*}{1,15} & \multirow{2}{*}{0,56} \\
\hline & $28 \%$ & $19 \%$ & $27 \%$ & $25 \%$ & & \\
\hline \multirow{2}{*}{ Ser aluno de medicina } & 15 & 7 & 20 & 42 & \multirow{2}{*}{1,03} & \multirow{2}{*}{0,6} \\
\hline & $20 \%$ & $17 \%$ & $24 \%$ & $21 \%$ & & \\
\hline \multirow{2}{*}{ Ética Médica* } & 21 & 4 & 12 & 37 & \multirow{2}{*}{7,37} & \multirow{2}{*}{0,025} \\
\hline & $28 \%$ & $10 \%$ & $14 \%$ & $18 \%$ & & \\
\hline \multirow{2}{*}{ Ser médico } & 8 & 8 & 12 & 28 & \multirow{2}{*}{0,56} & \multirow{2}{*}{0,76} \\
\hline & $11 \%$ & $19 \%$ & $14 \%$ & $14 \%$ & & \\
\hline \multirow{2}{*}{ Temas médicos } & 6 & 2 & 12 & 20 & \multirow{2}{*}{3,5} & \multirow{2}{*}{0,17} \\
\hline & $8 \%$ & $5 \%$ & $14 \%$ & $10 \%$ & & \\
\hline \multirow{2}{*}{ Faculdade e Universidade } & 6 & 5 & 5 & 16 & \multirow{2}{*}{1,32} & \multirow{2}{*}{0,52} \\
\hline & $8 \%$ & $12 \%$ & $6 \%$ & $8 \%$ & & \\
\hline \multirow{2}{*}{ Medicina e Sociedade } & 7 & 5 & 4 & 16 & \multirow{2}{*}{2,17} & \multirow{2}{*}{0,34} \\
\hline & $9 \%$ & $12 \%$ & $5 \%$ & $8 \%$ & & \\
\hline \multirow{2}{*}{ Vida pessoal } & 5 & 3 & 3 & 11 & \multirow{2}{*}{0,96} & \multirow{2}{*}{0,62} \\
\hline & $7 \%$ & $7 \%$ & $4 \%$ & $5 \%$ & & \\
\hline Temas não médicos & 2 & 1 & 4 & 7 & 076 & 069 \\
\hline & $3 \%$ & $2 \%$ & $5 \%$ & $3 \%$ & & \\
\hline
\end{tabular}

-Diferença estatisticamente significante entre os ciclos $(p<0,05)$.

O grupo de respostas relativas a "ser aluno de medicina" vem depois em ordem de importância (média $=21 \%$ ). O tema "ética médica" $(18 \%)$, que aparece a seguir, mostra os alunos do ciclo básico com um interesse significativamente maior ( $\mathrm{p}$ $=0,025)$ que os do ciclo clínico e do internato. Outros temas, como "ser médico", "temas médicos diversos", "faculdade e universidade" $\mathrm{e}$ "medicina e sociedade", aparecem na seqüência.

Os temas menos citados pelos alunos são aqueles relacionados à vida pessoal (média de $5 \%$ ) e temas fora da área médica (média de $3 \%$ entre os ciclos).

\section{Ranking dos Temas entre os Ciclos Básico, Clínico e Internato}

Se for estabelecido entre os ciclos um ranking dos temas mais e menos citados em cada ciclo, teremos a distribuição apresentada no Quadro 1.

\section{DISCUSSÃO}

O levantamento dos temas pelos alunos da faculdade apresentou um retrato interessante e importante das necessidades desses alunos ao longo de seu tempo de formação.

Considerando que esses temas foram sugeridos a partir da perspectiva de contar com o tutor - um profissional mais experiente para discuti-los -, podemos também compreendê-los como um diagnóstico situacional da formação oferecida pela faculdade.

Dentro da idéia de "diagnóstico", a análise, conteúdo e freqüência podem até mesmo ser considerados como um levantamento de "sinais e sintomas" dessa mesma formação. A partir dessa analogia com a prática médica, essa mesma análise pode então fornecer indicadores importantes sobre futuras e necessárias intervenções "terapêuticas" para a formação do futuro médico. 
QUADRO 1

Ranking dos Temas entre os Ciclos Básicos, Clínico e Internato

\begin{tabular}{|c|c|c|c|}
\hline Ranking & Cíclo Básico & Ciclo Clinico & Internato \\
\hline $1^{\circ}$ & Desenvolvimento profissional/carreira & Desenvolvimento profissional/carreira & Relação Médico-Paciente \\
\hline $2^{\circ}$ & Ensino-Aprendizagem & Ensino-Aprendizagem & Desenvolvimento profissional/carreira \\
\hline $3^{2}$ & Não indicação de temas & Ser médico & Não indicação de temas \\
\hline $4^{9}$ & Ética Médica & Não indicaçăo de temas & Ser aluno de medicina \\
\hline $5^{\circ}$ & Ser aluno de medicina & Ser aluno de medicina & Ética Médica \\
\hline $6^{\circ}$ & Relaçāo Médico-Paciente & Relação Médico-Paciente & Ser médico \\
\hline 72 & Ser médico & Faculdade e Universidade & Temas médicos \\
\hline $8^{\mathrm{e}}$ & Medicina e Sociedade & Medicina e Sociedade & Ensino - Aprendizagem \\
\hline $9^{\circ}$ & Faculdade e Universidade & Ética Médica & Faculdade e Univearsidade \\
\hline $10^{\circ}$ & Temas médicos específicos & Vida pessoal & Medicina e Sociedade \\
\hline $11^{\circ}$ & Vida pessoal & Temas médicos específicos & Temas não médicos diversos \\
\hline $12^{2}$ & Temas não médicos diversos & Temas não médicos diversos & Vida pessoal \\
\hline
\end{tabular}

É dentro dessa perspectiva e analogia (diagnóstico - sinais e sintomas - terapêutica indicada) que discutiremos nossos resultados.

Um primeiro ponto de discussão interessante diz respeito ao retorno dos questionários. Surpreendeu-nos a participação dos alunos do internato. Era esperado um retorno menor dos alunos dos últimos anos, uma vez que a dinâmica do internato, caracterizada pelo grande número de tarefas, e a dificuldade de localizar os internos nos ambulatórios e enfermarias do hospital-escola dificultariam a tarefa de entrega e recebimento do questionário.

No contexto da formação médica, pode-se compreender a maior participação dos alunos do ciclo básico na medida em que a faculdade é, sem dúvida, um espaço novo, estranho e gerador de ansiedade. Há muito que perguntar e querer saber para poder se adaptar.

Por outro lado, para os alunos do internato, sair da faculdade, terminar o curso é novamente deixar o conhecido, o seguro e enfrentar o estranho: a futura residência, a escolha da especialidade, o mercado de trabalho. Também muito há o que perguntar a quem já passou por esse momento. Daí, provavelmente, sua participação importante no retorno dos questionários.

Quanto à distribuição dos temas entre os ciclos, "desenvolvimento pessoal e de carreira" foi o mais citado em geral pelos alunos e é, de fato, a "alma" dos programas de mentoring em diferentes contextos e experiências ${ }^{8,9}$.

O objetivo da atividade tutorial (mentoring) é, sem dúvida, o suporte pessoal durante o desenvolvimento profissio- nal. Nesse sentido, os alunos parecem ter expectativas congruentes com o que a atividade se propõe oferecer.

Entretanto, é interessante discutir o fato de que este conjunto de temas relativos ao vir-a-ser profissional foi mais apresentado pelos alunos do ciclo básico e clínico do que pelos alunos do internato.

O que significa o fato de alunos ainda no início da formação estarem preocupados com questões como as atividades extracurriculares, o mercado de trabalho, a escolha da especialidade, a residência, o futuro da medicina, a atualização do conhecimento?

Rocco ${ }^{10}$, ao discutir a relação estudante-paciente, dizia que alguns alunos, ainda no primeiro ou segundo ano, já apresentam uma vontade precoce de usar a persona do doutor, acompanhando doentes em ambientes fora ou dentro do hospital-escola. Nossos resultados parecem apontar, então, outro aspecto dessa precoce persona de doutor: a relação estudantemercado de trabalho ou a relação estudante-futura especialização.

Ainda no início do curso, no momento da chegada, o término da jornada já aparece como fonte de curiosidade e talvez ansiedade: o que me espera como profissional? Que tipo de profissional devo ser? O que devo fazer, já no começo, para assegurar esse lugar?

Fazer ou não ligas, participar ou não de grupos de iniciação científica, acompanhar ou não tal ambulatório ou tal professor em suas pesquisas? As atividades extracurriculares e sua real importância para o futuro sem dúvida aparecem como demandas para orientação do futuro tutor. 
Quais as especializações possíveis, as perspectivas para cada uma, como será a prova de acesso à residência, onde encontrarei emprego, com qual remuneração?

Qual a relação deste tema com o currículo e a metodologia do ensino do curso de medicina?

Sabe-se que tais preocupações, desde o início do curso, podem prejudicar o desenrolar natural da própria formação, impedindo o aproveitamento das experiências próprias de cada fase da formação, e comprometer justamente o que tanto os preocupa: o futuro.

Por outro lado, não antecipadas, mas apropriadas no tempo, surgem como fundamentais para o ciclo básico e clínico as questões relativas ao tema "Ensino-aprendizagem": aprender a administrar o tempo, descobrir métodos de estudo eficientes, aprender a definir prioridades, a selecionar o conteúdo mais importante, em resumo, o quê e como aprender.

Essa demanda é bastante coerente com o que Millan e colaboradores ${ }^{11}$ definiram como "fase de desencanto". Terminadas as comemorações, dizem os autores, o aluno passa a ter contato, de fato, com o curso de medicina por meio das aulas, disciplinas e professores. Então, estão intensamente presentes as queixas relativas à falta de didática dos professores, à longa duração das aulas e ao excessivo volume de estudo.

Se para a totalidade dos alunos as questões referentes ao tema "relação médico-paciente" aparecem em terceiro lugar em ordem de importância, para os alunos do internato elas são, sem dúvida, prioritárias.

Dificuldades e fenômenos presentes nessa relação (agressividade, envolvimento emocional, comunicação, situações embaraçosas, conflitos e aspectos críticos relativos à morte e à sexualidade) são as questões mais demandantes de orientação para os alunos do $5^{\circ}$ e $6^{2}$ anos, e, no contexto da tutoria, as que mais necessitam da orientação do tutor.

O internato é o momento final da formação médica escolar, e, após longo período de estudo eminentemente teórico, o aluno se defronta finalmente com o paciente. Compara o que a escola ofereceu com o que pode pessoalmente aprender. $\mathrm{O}$ paciente, fora dos livros, é alguém que sofre, reclama, nem sempre colabora e exige soluções rápidas para seus problemas: como cuidar dele?

Por vezes, como assinala Rocco ${ }^{10}$, o aluno vê no doente a ignorância que julga ter e outras vezes se sente invadindo a intimidade do paciente ao perguntar tópicos da anamnese, como, por exemplo, hábitos sexuais. Em relação à morte, Zaidhaft e colaboradores ${ }^{12}$ discutem o quanto a relação estudante-morte, baseada na relação com o cadáver nas aulas de anatomia, pode ser depois dificultadora quando a rela- ção, no internato, passa a ser estudante-paciente que está morrendo.

A "não indicação de temas" é o grupo temático que surge depois na ordem de importância para os alunos em geral, numa proporção até bastante próxima dos temas anteriores (ensino-aprendizagem e relação médico-paciente).

Deixar em branco o espaço reservado aos temas (embora tenham respondido às questões de indicação e contra-indicação de professores como tutores) ou responder com um "sei lá", "tanto faz" podem indicar desinteresse, desestímulo e recusa da proposta de tutoria. Mas podem também indicar dificuldade ou incapacidade de identificar suas próprias necessidades e desejos frente ao curso e à formação oferecida.

Nesse sentido, é interessante observar que o próximo grupo temático é exatamente o que diz respeito a "ser aluno de medicina".

Este tema envolve desde a questão da vocação médica até as dificuldades encontradas pelos alunos no curso médico ao longo do tempo. Fazem parte dele os problemas acadêmicos em geral, mas especialmente os problemas emocionais que acompanham cada fase do curso (pressão psicológica, cansaço, estresse, depressão, ansiedade e até mesmo abuso de substâncias). Qualidade de vida do aluno e seus direitos e deveres compõem também o quadro geral.

Neste tema, a necessidade de discutir a vocação surge mesmo no final do curso, entre os internos.

Millan e colaboradores ${ }^{11}$ relata que as crises de desistência aparecem praticamente durante todo o curso. Se no início do curso o aluno acredita que é cedo para tomar uma decisão, pois ainda não conhece toda a medicina, nos anos seguintes surge a idéia de que parar o curso é perder "todos esses anos da vida". Especialmente no final do curso, a escolha da especialidade reaviva as razões da própria escolha da medicina e, nesse sentido, compreende-se que este momento final desencadeia questionamentos vocacionais.

O grupo temático "ética médica" aparece a seguir e evidencia a importância que a discussão de aspectos éticos tem para os alunos dos dois primeiros anos (ciclo básico). Ainda no início do curso, os alunos sugerem a discussão não apenas de temas polêmicos, como aborto, eutanásia e questões dilemáticas de decisão, mas também dos aspectos legais relativos à responsabilidade do médico frente aos erros, processos e leis.

Será a menor participação deste conjunto de temas nos anos subseqüentes sinal de menor interesse ou de maior conhecimento, experiência e vivência dos alunos?

Como refere Hossne ${ }^{13}$, será que o ensino e a discussão de aspectos éticos são considerados acessórios ou "perfumaria" ao se iniciar o ciclo profissionalizante? 
Nas questões ligadas ao tema "ser médico" - como é o seu cotidiano profissional, como o médico concilia sua vida profissional e pessoal, como deve ser a conduta nos primeiros anos de formado, quais são as dificuldades da profissão, inclusive seus aspectos financeiros - , os alunos se preocupam ainda em discutir a qualidade de vida do médico: como o médico cuida de si mesmo e administra o estresse da profissão? Como assinalou Bellodi ${ }^{4}$, embora muito já se tenha dito a respeito da onipotência como característica essencial da identidade médica, discutem-se hoje mais as dificuldades do exercício da medicina e começa-se a falar mais da fragilidade de quem exerce a medicina nessas condições.

Os "temas médicos", sejam disciplinas específicas, sejam casos clínicos ou temas médicos diversos, surgem como a próxima "pauta" para as reuniões de tutoria. Podem indicar tanto deficiências da formação para as quais os alunos demandam maior atenção, quanto uma compreensão incorreta dos objetivos da tutoria, considerados como complementação do estudo acadêmico.

Temas listados com menor freqüência pelos alunos, como os ligados à "faculdade e universidade", fazem com que questionemos se há uma falta do chamado "espírito universitário" entre eles.

Arruda $^{14}$ apresenta tal conceito como a capacidade de conviver com idéias diferentes, num ambiente que busca o progresso da ciência e a preparação das elites culturais, políticas e profissionais do mundo moderno. Nesse sentido, talvez ele precise ser alvo de investimento e possa ser bastante beneficiado ao se constituir tema de discussão na tutoria.

A mesma análise se aplica ao tema "medicina e sociedade" com a reflexão a respeito de trabalhos sociais do aluno e do médico frente à comunidade e sobre a política e o sistema de saúde no Brasil.

Por fim, há que se destacar que os temas menos citados são os ligados à "vida pessoal" do aluno e do médico (especialmente quanto ao lazer e às relaç̃es familiares) e a "temas não médicos" (culturais e científicos).

Há diversas interpretações desse resultado. Pode ser um sinal de que o aluno não deseja ser "invadido" em seus aspectos mais pessoais ou não deseje compartilhá-los com os demais colegas, uma vez que a competição e a representação dos colegas como rivais são um aspecto marcante do curso médico.

Pode representar também a dificuldade de "enxergar" num docente da faculdade alguém próximo, com quem se possa conversar a respeito dessa vida pessoal.

Ou talvez, e mais provavelmente, também pode estar demonstrando o quanto o curso médico "rouba" tempo e "moti- vação" para se continuar em contato com os aspectos não médicos em geral (aí incluída a vida pessoal). Bom tema, podemos assinalar, para que também os tutores pensem a respeito...

\section{Conclusões}

O temário elaborado a partir das respostas dos alunos teve um importante papel na orientação dos futuros tutores. Evidenciou as principais áreas de interesse dos alunos, mostrou as diferenças ao longo dos vários anos e permitiu vislumbrar as possíveis utilizações do espaço da tutoria no atual programa: para todos os alunos, o desenvolvimento profissional, a necessidade de discutir a relação médico-paciente; para o internato e para os alunos dos ciclos básico e clínico, a demanda por orientação de aspectos de ensino-aprendizagem.

Este trabalho permitiu uma visão dos temas sugeridos e sua ordem de importância, para dar-lhes uma especial atenção no processo educacional Programa Tutores FMUSP, que busca, cada vez mais, dar uma formação integral ao futuro médico.

As atividades da tutoria deverão incluir a discussão dos temas assinalados neste trabalho e servirão de base para algumas intervenções que poderão melhorar a formação do médico como pessoa e profissional.

\section{Agradecimentos}

Agradecemos a todos os tutores e alunos que tornam o Programa Tutores uma experiência viva e produtiva a ser relatada.

\section{REFERÊNCIAS BIBLIOGRÁFICAS}

1. Wolf TM. Stress, coping and health: enhancing well being during medical school. Med Educ 1994; 28: 8-17.

2. Coles C. Medicine and stress. Med Educ 1994; 28: 3-4.

3. Coles C. Support for medical students in the United Kingdom. Med Educ 1993; 27: 186-87.

4. Bellodi PL. O clínico e o cirurgião: estereótipos, personalidade e escolha de especialidade médica. São Paulo: Casa do Psicólogo, 2001.

5. Woessner R; Honold M; Stehr SN; Steudel WI. Faculty mentoring programme - ways of reducing anonymity. Med Educ 1998; 32: 441-43.

6. Freeman R. Faculty mentoring programmes. Med Educ 2000; 34: 507-08.

7. Bellodi PL; Martins MA. Projeto Tutores: da proposta à implantação na graduação da Faculdade de Medicina da Universidade de São Paulo (FMUSP). Rev HU 2002; 11: 52-58. 
8. Kalet A; Krackov S; Rey M. Mentoring for a new era. Acad Méd 2002; 77: 1171-1172.

9. Murr AH; Miller C; Papadakis M. Mentorship through Advisory Colleges. Acad Med 2002; 77: 1171-1173.

10. Rocco RP. Relação estudante-paciente. In: Mello Filho J e cols. Psicossomática hoje. Porto Alegre: Artes Médicas; 1992.

11. Millan LR; De Marco OLN; Rossi E; Millan MPB; Arruda PV. Alguns aspectos psicológicos ligados à formação médica. In Millan e cols. O universo psicológico do futuro médico: vocação, vicissitudes e perspectivas. São Paulo: Casa do Psicólogo, 1999.

12. Zaidhaft S. et al. O estudante de medicina e a morte. In: Mello Filho J e cols. Psicossomática hoje. Porto Alegre: Artes Médicas; 1992.

13. Hossne WS. Educação médica e ética. In: Marcondes E; Lima-Gonçalves E, coord. Educaçāo médica. São Paulo: Sarvier, 1998.
14. Arruda PV. As relações entre alunos e professores. In Millan e cols. O Universo psicológico do futuro médico: vocaçāo, vicissitudes e perspectivas. São Paulo: Casa do Psicólogo, 1999.

\section{Endereço para correspondência}

Patrícia Lacerda Bellodi

Rua Dona Luiza Júlia - 12/ apt $^{2} 62$ - Itaim Bibi

04542-020 - São Paulo — SP

e-mail: ptbellodi@uol.com.br

Tânia Martinho

e-mail: taniamart@aol.com

Bianca Massaroppe

e-mail: bimassaroppe@hotmail.com

Milton de Arruda Martins

e-mail: mmartins@usp.br 